\title{
SABERES GEOMÉTRICOS NO CURSO PRIMÁRIO: UMA DISCUSSÃO SOBRE O MOVIMENTO DE SEUS MÉTODOS E COTEÚDOS
}

GEOMETRIC KNOWLEDGE ON THE PRIMARY EDUCATION: A DISCUSSION ON THE MOVEMENT OF ITS METHODS AND CONTENTS

\author{
CAMARA, Alexsandra \\ ale-prof@hotmail.com \\ PUCPR - Pontifícia Universidade Católica do Paraná \\ PINTO, Neuza Bertoni \\ neuzabertonip@gmail.com \\ REAMEC- UFMT- Rede Amazônica de Educação em Ciências e Matemática
}

RESUMO Nas primeiras décadas do século XX (1903-1930), tornava-se necessária a implantação de uma reforma na instrução pública da escola de primeiras letras, onde conteúdos e métodos de ensino da época foram colocados em debate. Diante essa necessidade, o objetivo deste texto é trazer uma discussão sobre os diferentes conteúdos e abordagens de métodos de ensino dos saberes geométricos, considerando como fontes de pesquisa programas de ensino, relatórios e livros didáticos utilizados na primeira república paranaense. Fizemos uso do ferramental teórico-metodológico proveniente da História Cultural e concluímos que, no período de estudo, vários métodos de ensino se faziam presentes em discussões, em documentos e possivelmente em práticas que envolviam os saberes geométricos.

PALAVRAS-CHAVE: Conteúdos. Ensino Primário. História da Educação Matemática. Métodos de Ensino. Saberes Geométricos.

ABSTRACT Content and teaching methods were put into debate in the first decades of the twentieth century (1903-1930). The implementation of primary education reform in public education schools was made necessary. The purpose of this text is to bring a discussion of different contents and approaches on geometrical knowledge teaching methods. Education programs, reports and textbooks used in the first republic of Parana were the research sources. We made use of theoretical and methodological tools from the Cultural History and concluded that several teaching methods presented themselves in the discussions, documents and possibly practices involving geometric knowledge.

KEY-WORDS: Contents. Geometrical knowledge. History of Mathematics Education. Primary Education. Teaching methods.

\section{CONSIDERAÇÕES INICIAIS}


O período do final do Império e início da República paranaense foi marcado por inúmeros conflitos políticos, econômicos e sociais, fazendo-se necessária a implantação de uma instrução pública organizada, obrigatória e que tivesse como objetivo educar o homem para a nova sociedade. Deste modo, a escola seria responsável pela formação do cidadão, difundindo conhecimentos considerados condizentes ao progresso da nação. A instrução deveria estar atenta ao novo homem que atendesse às exigências do desenvolvimento econômico, industrial e político pelo qual o país passava (SOUZA, 2004).

Tendo em vista esta necessidade, alguns conteúdos e métodos de ensino da época foram considerados tradicionais, dando-se início ao debate sobre questões políticas da educação, assim como o desenvolvimento de uma organização pedagógica mais eficaz da escola primária.

Segundo Valente (2015), há muitas discussões sobre métodos e processos de ensino para a escola primária a partir de finais do século XIX, mais intensamente no âmbito da alfabetização. Porém, há muito menos estudos sobre esse tema para o ensino da Matemática, o que o leva a apontar a importância de análise do modo como se estruturam os métodos e conteúdos matemáticos ao longo da história.

Dedicando-nos à análise de trabalhos e publicações sobre a matemática escolar do ensino primário, percebemos a necessidade de intensificar estudos sobre o ensino da Geometria. Segundo Souza (2009), há uma defasagem em investigações que envolvem a história de cada uma das matérias do programa da escola primária, e mais especificamente a Geometria.

Diante das necessidades brevemente apresentadas, este texto procura trazer uma discussão das diferentes abordagens sobre métodos, considerando a importância de análise do modo como se estruturam os saberes geométricos nas três primeiras décadas do século XX no ensino primário do estado do Paraná.

\section{MÉTODOS E CONTEÚDOS NAS DISCIPLINAS ESCOLARES}

A história das disciplinas escolares carrega a concepção da História Cultural, concebida por Chartier (1990) como a história das práticas e das representações. Uma história enquanto representação e não cópia de um passado que deixou 


\section{Atos de Pesquisa em Educação - ISSN 1809-0354 \\ Blumenau, v. 12, n.2, p.324-345, mai./ago. 2017 \\ DOI: http://dx.doi.org/10.7867/1809-0354.2017v12n2p324-345}

vestígios e que poderá revelar usos que os sujeitos fizeram dos objetos culturais que foram disponibilizados.

Sabemos que as disciplinas, como um produto cultural, são responsáveis pelos saberes escolares e por orientações didático-pedagógicas que procuram orientar o processo de seu ensino. Portanto, o historiador necessita de "documentos que contenham vestígios da prática cultural investigada. No caso da cultura escolar, documentos que interessam ao pesquisador são os portadores de normas, códigos e condutas escolares" (PINTO, 2014, p. 131).

Estamos cientes de que uma disciplina escolar não é apenas constituída de conteúdos e que este não é o único olhar que devemos ter no sentido de compreendermos sobre a finalidade que cumpre na escolarização. Como afirma Chervel (1990), os conteúdos são apenas meios utilizados para alcançar um fim e um momento ideal para a pesquisa é quando uma disciplina escolar é alvo de alguma mudança, quando novas finalidades e objetivos lhe são necessários.

Para o desenvolvimento de nossa problemática cabe retomar a discussão sobre ciência, pedagogia e saberes escolares realizada por André Chervel. Com relação aos conteúdos de ensino o autor acredita que para a opinião comum ainda prevalece que "A escola ensina ciências, as quais fizeram comprovações em outros locais. Ela ensina a Gramática porque a gramática, criação secular dos linguistas, expressa a verdade da língua" (CHERVEL, 1990, p.180).

Nesse sentido, ainda acredita-se que o conteúdo discutido nas escolas é o mesmo que foi desenvolvido pelos cientistas ao longo de nossa história. Contrapondo-se a essa opinião, Chervel ressalta a importância de compreender que as disciplinas escolares são na verdade o resultado histórico do que a escola produz ao longo de sua existência. Vale lembrar que em pesquisa realizada por Chevallard $(1985)^{1}$ constatou-se que conteúdos matemáticos introduzidos há vinte anos no ensino secundário francês não tem muito em comum com os conteúdos científicos que servem de sustentação a esses conteúdos escolares.

Essa visão comum de perceber os conteúdos também pode estar relacionada à atribuição da pedagogia como "necessidade de simplificar, na verdade vulgarizar,

\footnotetext{
${ }^{1}$ Utilizando da noção de transposição didática os educadores matemáticos medem hoje a distância existente entre o "saber erudito" e o "saber ensinado".
} 
para um público jovem, os conhecimentos que não se the podem apresentar na sua pureza e integridade" (CHERVEL, 1990, p.181). Nesse contexto a pedagogia desenvolve uma metodologia que permite um trabalho com os conteúdos de maneira que possam ser ensinados aos estudantes. Esta realidade nos apresenta uma visão de que de um lado estariam os conteúdos da Ciência e de outro os métodos de ensino da Pedagogia. Porém, André Chervel aponta que:

Excluir a pedagogia do estudo dos conteúdos é condenar-se a nada compreender do funcionamento real dos ensinos. A pedagogia, longe de ser lubrificante espalhado sobre o mecanismo, não é senão um elemento desse mecanismo; aquele que transforma os ensinos em aprendizagens. (CHERVEL, 1990, p.182)

Em concordância com a postura teórico-metodológica apresentada por André Chervel, procuramos discutir a nossa problemática não separando método e conteúdo para o estudo das disciplinas escolares. Neste sentido, nossa discussão se desenvolve na análise de conteúdos e métodos como elementos essenciais para a compreensão da forma como se organizam os saberes geométricos nas escolas de primeiras letras.

\section{OS SABERES GEOMÉTRICOS E OS MÉTODOS DE ENSINO}

Muitas discussões sobre métodos ocorreram ao longo da história da humanidade. Método, termo originário do latim methodus, tem um significado etimológico de necessidade ou de demanda, sendo definido como um modo de proceder, uma maneira de agir, um meio ou um caminho para se atingir um fim. Há duas espécies de métodos fundamentais do conhecimento que são o sintético e o seu oposto, o analítico; em que seus usos no ensino da Matemática se fazem presentes em diversos textos como, por exemplo, na obra Introdução à Arte Analítica ${ }^{2}$, de François Viète (1540 -1603).

2 Correa (2009) analisa uma das obras de François Viète (1540-1603), conhecido entre os historiadores da matemática como o pai da álgebra moderna. No entanto, foi na tentativa de resolver problemas geométricos que ele foi levado a propor uma nova maneira de se fazer matemática. Em sua In Artem analyticem Isagoge (Introdução à Arte Analítica), obra publicada em 1591, Viète expôs o método que se tornaria fundamental para o pensamento matemático. 


\author{
Atos de Pesquisa em Educação - ISSN 1809-0354 \\ Blumenau, v. 12, n.2, p.324-345, mai./ago. 2017 \\ DOI: http://dx.doi.org/10.7867/1809-0354.2017v12n2p324-345
}

Encontra-se na Matemática uma certa maneira de procurar a verdade, que diz-se ter sido primeiramente inventada por Platão, que Theon chamou 'Análise' e que, para ele, define a suposição daquilo que procuramos com se estivesse concedido para chegar a uma verdade procurada, por meio de conseqüências; ao contrário, a 'Síntese' é a suposição de uma coisa concedida para chegar ao conhecimento daquilo que procuramos pelo meio de consequências. (VIĖTE, 1630, p. 4)

De uma maneira simplificada, podemos dizer que o método sintético é aquele que parte dos elementos para as suas combinações, enquanto que no método analítico o todo que é dividido em seus elementos constitutivos. O método sintético é progressivo, enquanto o analítico é regressivo, vai do objeto às condições que o possibilitam.

Considerando nossa época de estudo, nos situamos diante a urgência de que a escola paranaese se adequasse às novas necessidades da sociedade. A formação desenvolvida nas escolas até então era insuficiente, centrada em um ensino abstrato, baseado na memória e que valorizava mais a repetição do que a compreensão dos objetos estudados.

Repensar os conteúdos escolares e métodos de ensino era considerado elemento essencial diante a situação apresentada; uma vaga pedagógica se desenvolve e um novo método vem ao encontro dos métodos sintético e analítico. Temos então a Pedagogia Moderna que procurava o ensino intuitivo; "este nome de método intuitivo corresponde ao método experimental em uso quando se pretende os graus mais elevados do ensino. A experimentação é um procedimento aperfeiçoado de observação" (VALDEMARIN, 1998, p. 70).

Pestalozzi (1746-1827) é considerado o criador do método intuitivo, pois apoiado em estudos de Comenius, aprofundou e vulgarizou a expressão "ensino intuitivo" (LOURENÇO FILHO, 2002). Defendeu uma educação fundamentada pela experiência e a observação como necessária para a construção do conhecimento.

Diante a necessidade de um novo método de ensino em terras parananeses nos perguntamos sobre quais seriam os passos, os vestígios do uso desse método. Como estavam sendo realizadas as discussões sobre métodos de ensino, mais especificamente para os saberes geométricos, nas escolas primárias paranaenses?

Em 1901, o Regulamento de Instrucção Pública assinado por Octávio Ferreira do Amaral e Silva, Secretário de Estado dos Negócios do Interior, Justiça e 
Instrucção Pública do Estado do Paraná, em seu parágrafo 14, do artigo 62, estabelecia que caberia ao professor no desenvolvimento de suas práticas "dar ao ensino o caracter essencialmente prático, tendo em vista as aplicações às necessidades da vida e a utilidade directa" (PARANÁ, 1901, p. 101)

O Decreto $\mathrm{n}^{\circ} 263$, de 22 de outubro de 1903, apresentou o Regimento Interno das Escolas Publicas do Estado do Paraná, estabelecendo previsões quanto ao programa de ensino, quanto a matrícula e frequência às aulas, quanto aos professores e a todos os elementos referentes ao funcionamento das escolas e de sua inspeção. Os artigos $3^{\circ}$ e $4^{\circ}$ desse regimento comentam sobre os métodos de ensino que deveriam ser desenvolvidos.

$3^{\circ}$ - O processo de ensino deve ser intuitivo, visando-se desenvolver no alumno a faculdade da observação, habituando-o pensar por si mesmo. Exercitando-se-lhe a memoria, cumpre evitar que ele decore automaticamente, como papagaio; transmita-se-lhe a idéa, para ele reproduzir por suas próprias palavras, quando possível, sem se escravizar ás palavras do livro. $4^{\circ}$ - As lições devem ser mais praticas e concretas que theoricas e abstractas, promovendo-se gradualmente o desenvolvimento das faculdades infantis. (PARANÁ, 1903, p. 92)

A preocupação com os métodos também se faz presente no Regulamento Orgânico do Ensino Público do Estado do Paraná de $1909^{3}$, preconizando um ensino de caráter intuitivo e prático que deveria ser "transmitido de acordo com os respectivos programas e pelos methodos autorizados pelo Conselho Superior de Ensino" (PARANÁ, 1909, Art. 74, p. 134) e estabelecendo que os professores deveriam pensar as suas práticas de modo que as crianças desenvolvessem "as suas inclinações expontaneas para os factos concreto, por meio do ensino de cousas" (Art. 75, p. 134).

As observações sobre método de ensino, apresentadas pelos primeiros regulamentos no século $\mathrm{XX}$, indicam de forma explícita a necessidade do uso do método intuitivo. A observação e a realização de atividades práticas e concretas são indicadas como elementos essenciais no desenvolvimento deste método.

\footnotetext{
${ }^{3}$ Documento assinado pelo Presidente do Estado, senhor Francisco Xavier da Silva, em 15 de outubro de 1909, período em que Claudino Rogoberto Ferreira dos Santos atuou como Diretor da Instrução Pública.
} 


\title{
Atos de Pesquisa em Educação - ISSN 1809-0354 \\ Blumenau, v. 12, n.2, p.324-345, mai./ago. 2017 \\ DOI: http://dx.doi.org/10.7867/1809-0354.2017v12n2p324-345
}

No ano de 1906, ocorreu a divulgação do primeiro número do periódico $A$ Escola, pelo órgão do Grêmio dos Professores Públicos do estado do Paraná, tendo como Diretor o Professor Dario Velozzo e o redator chefe, o Professor Sebastião Paraná ${ }^{4}$. Havia uma parte da revista que era dedicada a apresentação de relatórios de professores de escolas públicas do estado, conforme consta no Regulamento da Instrução Pública do Estado (1901) em seu art. 62, no 11, que coloca a obrigação dos professores em apresentarem ao final de cada ano um relatório sobre o estado de suas escolas e observações sobre o andamento dos alunos.

No relatório publicado na revista A Escola, v.2 (1906), escrito pela professora Josephina Carmem Rocha, que ministrava aulas no $2^{\circ}$ grau do ensino primário, na Escola Carvalho, há menção sobre o método de ensino adotado.

\begin{abstract}
O ensino é intuitivo, sendo ministrado simultaneamente aos alumnos aptos para o estudo em classe. [...]. Assim é que tendo procurado desenvolver o gosto e a dedicação ao estudo, tornando-o pratico, fazendo com que os alumnos depois de uma explicação de grammatica, por exemplo, aplique-a, já fazendo analyse das lições, já escrevendo cartas e fazendo descripções de objetos do seu conhecimento; o mesmo faço com relação á todas as outras matérias que fazem parte do programma de ensino, partindo sempre do simples para o composto, do concreto para o abstrato, do estudo de cada uma das partes para o estudo de um todo.(ROCHA, 1906, p. 44-45)
\end{abstract}

A ideia do ensino partindo do simples para o composto e do concreto para o abstrato deixa clara a intenção de um trabalho com o método intuitivo. No entanto, o fato de pensar o ensino caminhando da parte para o todo nos mostra uma característica do método sintético. Sendo assim, o relatório apresentado por Rocha (1906) indica que o método adotado poderia ser o intuitivo-sintético.

Conforme relatório do Secretário do Interior, Justiça e Instrução Pública, Enéas Marques dos Santos, ao presidente do estado do Paraná, Affonso Alves de Camargo, o método de ensino no grupo escolar modelo do Paraná deveria ser realizado "com aplicação do methodo analytico e provimento completo do material" (PARANÁ, 1917, p. 13).

\footnotetext{
${ }^{4}$ Dario Velozzo, fundador da revista e professor da Escola Normal, intelectual que se opunha ao ideário católico e aos dirigentes eclesiásticos. Sebastião Paraná, professor catedrático de Geografia Geral e do Brasil no Ginásio Paranaense e na Escola Normal de Curitiba. Autor de inúmeros livros entre eles, História do Paraná e O Brasil e o Paraná, obra que alcançou vinte e duas edições.
} 


\section{Atos de Pesquisa em Educação - ISSN 1809-0354 \\ Blumenau, v. 12, n.2, p.324-345, mai./ago. 2017 \\ DOI: http://dx.doi.org/10.7867/1809-0354.2017v12n2p324-345}

A preocupação com o método analítico ampliou-se na década de 1920 com Cesar Pietro Martinez ${ }^{5}$, Inspetor Geral do Ensino.

\begin{abstract}
Quem ensina a ler pelo método analytico, segue caminho idêntico em relação a linguagem, calligraphia, a arithmetica, a geografia, á historia, ao desenho. Si, de facto, for o educador conhecedor das bases fundamentais do methodo, tornara o ensino variado, de anno para anno, de lição para lição, acrescentando, suprimindo, substituindo, inovando em summa; de maneira a lucrar não somente o aluno, mas o próprio professor que se compraz em dar uma feição variada e, portanto, mais sympathica às suas lições. (PARANÁ, 1924, p. 19)
\end{abstract}

Percebe-se a preocupação com relação à aplicação do método analítico para a alfabetização das crianças e também para outras disciplinas escolares. Mas em que consistia o método analítico no ensino primário? Como este método era pensado para o ensino dos saberes geométricos?

Oswaldo Piloto ${ }^{6}$ escreveu, em 1926, um material para os professores intitulado Metodologia de Geometria, traduzido de Juan Patrascoiu ${ }^{7}$ e adaptado aos programas do estado do Paraná. O texto apresenta sete lições, a saber: histórico, importância da Geometria, métodos de ensino, processos de ensino, vícios do ensino, modelo de aula e plano tipo para as lições de forma.

O autor coloca que para o desenvolvimento do ensino da Geometria há duas tendências contrárias: uma em que os professores vão dos estudos das linhas e das superfícies aos sólidos e outra, ao contrário, estudam primeiro os corpos para depois tratarem das superfícies e das linhas. Pilotto coloca que devemos preferir a segunda, pelas razões seguintes:

5 Convidado para exercer o cargo de Inspetor Geral da Instrução Pública do estado do Paraná, o professor da Escola Normal de Pirassununga do estado de São Paulo, César Prieto Martinez, exerceu a função de 1920 à 1924. Sua atuação trouxe muitas mudanças para a escola primária do Paraná, sobretudo no que se refere à produção de documentos normativos detalhados, à expansão e modernização do ensino primário no estado.

6 Osvaldo Pilotto (1901-1993), engenheiro agrônomo, foi professor do Instituto de Educação do Paraná e mais tarde da Universidade Federal do Paraná, na cátedra de Filosofia e Ciências Humanas. Ocupou diversas funções relacionadas à Educação no Estado, tendo intensa produção na área da história, sobretudo, relacionada à Imprensa, como é o caso do famoso estudo "Cem anos de Imprensa no Paraná" (PILOTTO, 1976). Na Academia Paranaense de Letras foi ocupante da cadeira número 2, justamente, a que leva o nome de Cândido Lopes, dono do primeiro jornal paranaense. (ANJOS, 2011)

$7 \mathrm{O}$ pedagogo argentino Juan Patrascoiu, adepto às concepções de Herbart, influenciou Lysímaco Ferreira da Costa nas reformas da Escola Normal do Paraná. (MIGUEL, 1997). 


\author{
Atos de Pesquisa em Educação - ISSN 1809-0354 \\ Blumenau, v. 12, n.2, p.324-345, mai./ago. 2017 \\ DOI: http://dx.doi.org/10.7867/1809-0354.2017v12n2p324-345
}

$1^{\circ}$ - As primeiras lições de geometria devem tratar de assuntos concretos para que sejam comprehendidas pelos alunnos. Ora, os corpos geometricos são cousas concretas enquanto que as linhas, o ponto, as superfícies são puras abstrações que não tem existência real fora dos corpos.

$2^{\circ}$ - O estudo dos sólidos requer a actividade da junção perceptiva, enquanto que as linhas, os ângulos, etc, são produtos exclusivos da abstração.

$3^{\circ}$ - Não é fácil ir dos conhecimentos abstratos (linhas) aos concretos (corpos). (PILOTTO, 1926 p. 9-10)

Nas etapas apresentadas por Oswaldo Pilotto para o ensino da Geometria é indicada a necessidade de se iniciar os assuntos utilizando objetos concretos, partindo do estudo dos sólidos geométricos para depois realizar o estudo das figuras planas. Percebe-se a intenção de um ensino de saberes geométricos voltado para o método intuitivo (o concreto, o sensível) e analítico (do todo para as partes).

Esta concepção apresentada por Pilotto também foi discutida em artigo de Leme da Silva (2015). A autora analisa as ideias sobre o ensino de saberes geométricos apresentadas por Oscar Thompson na revista $A$ Eschola Pública (1895), verificando que a proposta apresentada "conjuga de forma harmoniosa os princípios dos métodos intuitivo e analítico" (LEME DA SILVA, 2015, p.5). Sendo assim, tanto na proposta de Pilotto, como na de Thompson, mostram-se presentes características dos métodos intuitivo e analítico para o ensino dos saberes geométricos no ensino primário.

\title{
a. MÉTODOS E CONTEÚDOS NOS PROGRAMAS DE ENSINO
}

Os documentos legais que se destinavam a instrução pública nas primeiras décadas da república sofreram inúmeras aprovações e revogações, produzindo vários documentos e muita confusão no que se referem às normas que estariam em vigência.

A legislação de 1901 assim como o Regimento Interno das Escolas Públicas do Estado do Paraná de 1903 determinavam para o primeiro grau o ensino de Desenho Linear e para o segundo grau ${ }^{8}$ noções de Geometria Plana. Para Desenho Linear eram sugeridos os conteúdos de linhas, ângulos, triângulo e outros polígonos,

\footnotetext{
${ }^{8}$ Em cada grau do ensino primário deveria constar dois anos ou duas séries, conforme parágrafo único do Regimento Interno das Escolas Publicas do Estado do Paraná (1903)
} 
enquanto que para a geometria plana as sugestões eram: linhas, ângulos, polígonos, circunferências, outras figuras formadas por linhas curvas e algumas aplicações práticas. Já a matéria de trabalhos manuais, indicada para os dois graus, era direcionada somente para meninas e estava relacionada à costura, bordado e corte.

Neste programa não são observadas indicações do trabalho com sólidos geométricos e quanto à matéria de Desenho verificamos a sua relação com a de Geometria, a mesma relação já percebida no estado de São Paulo no período do Império (VALENTE, 2012) e na primeira república (FRIZZARINI, 2014).

Com relação ao Regulamento Orgânico do Ensino Público do Estado do Paraná de $1909^{9}$, são destacadas as matérias de Aritmética, Geometria, Desenho a mão livre e Desenho geométrico elementar para o ensino primário. Para Geometria devem ser consideradas noções fundamentais e conhecimento prático das principais formas geométricas. Para a matéria de Desenho geométrico elementar, não há sugestão de conteúdos a serem desenvolvidos. Os conteúdos sugeridos para a matéria de Desenho a mão livre eram desde o traçado de linhas (sem o auxílio de instrumentos) até o esboço de objetos, seres e pequenas paisagens.

Em $1916^{10}$ o Conselho Superior do Ensino Primário do Estado do Paraná apresenta o documento Programas de Ensino e sua Execução nos Institutos Públicos do curso Primário. Com relação aos saberes geométricos o programa apresenta: Desenho Linear ( $1^{a}$ série e $2^{a}$ séries), Geometria ( $3^{a}$ e $4^{a}$ séries), Desenho do natural e da imaginação ( $3^{a}$ e $4^{a}$ séries) e Trabalhos Manuais em todas as séries. Verifica-se que para o ensino de Geometria deveriam ser realizadas aplicações úteis e soluções de problemas. No que se refere ao ensino de Desenho na $2^{a}$ série, deveriam ser introduzidos os trabalhos com objetos comuns e na $4^{a}$ série o desenho de imaginação. A matéria de Trabalhos Manuais apresenta para os meninos, entre outros conteúdos, o uso de lápis e régua para quadricular as pautas

\footnotetext{
${ }^{9}$ Este regulamento, aprovado por Francisco Xavier da Silva, foi colocado em execução, porém revogado depois de quatro meses. A justificativa é pautada "na constatação do desajustamento entre as realidades escolar e política, de um lado, e legislação e normatização pedagógica, de outro, produziu parecer desolador diante da distância de um modelo civilizador republicano" (SOUZA, 2004, p.99).
} 
e a construção de sólidos geométricos em papelão, enquanto que para as meninas os conteúdos estão baseados em corte, bordado e crochet.

Entre as questões em pauta estava a necessidade de edificar uma "Escola Modelo" onde o decreto $n^{\circ} 978$, de 28 de dezembro de 1916 criou o primeiro grupo escolar modelo sendo a Casa Escolar Xavier da Silva considerada como o local adequado para o funcionamento da proposta. Em 1917, um programa de ensino para a escola modelo, extensivo a todos os grupos escolares do Estado, trazia maiores detalhes no que se refere aos conteúdos e procedimentos que deveriam ser desenvolvidos no ensino primário. Um outro programa, que foi publicado em 1921, também foi dividido por ano e disciplinas. Em ambos os programas, de 1917 e 1921, são apresentadas a Aritmética, a Geometria e o Desenho para os quatro anos do ensino primário, com especificações de conteúdos que deveriam ser trabalhados.

O estudo de Geometria, apresentado nesses programas, inicia com os sólidos geométricos (esfera, hemisfério, cone, cilindro, cubo, paralelepípedo, prisma e pirâmide), posteriormente são sugeridos os estudos de ponto, reta, curva, ângulo, triângulos, quadriláteros, noção de polígonos, circunferência, volume de prisma, divisão de segmentos em partes proporcionais e áreas de triângulos e quadriláteros por triangulação. A realização de desenhos deve ocorrer no quadro, no papel e em terrenos. Inicialmente não há especificações de uso de instrumentos, porém nos anos seguintes é sugerido o uso de esquadro, compasso e de cordéis. Nos últimos anos há a sugestão da realização de exercícios práticos.

No programa de Desenho são sugeridos desenhos de objetos, animais, plantas, folhas, paisagens e de sólidos geométricos. Os desenhos devem ser realizados do mais simples para o mais complexo, com dificuldades crescentes a cada situação desenvolvida. Podem ser feitos a lápis ou a giz de cor no quadro negro e no papel, à vista do modelo natural, e podem ser copiados ou inventados pelos alunos.

Quanto à matéria de Trabalhos Manuais, para esses dois últimos programas analisados, também se percebe um nível gradativo de dificuldade durante o desenvolvimento do ensino primário. Entre outros conteúdos (horticultura, jardinagem, costura, bordado, etc) são sugeridos o dobramento de papel (objetos usuais: chapéus, barquinhas, caixinhas, casinhas, etc) e a reprodução de sólidos 
geométricos em argila; nos anos finais aparece o uso de esquadro, compasso e metro. Para a seção feminina continuam sendo sugeridos trabalhos de costura, bordados e crochet.

Nesta breve análise dos saberes geométricos presentes nos programas do ensino primário nas primeiras décadas da república, percebemos que mudanças mais significativas realmente ocorrem com o Programa da Escola Modelo (1917) conforme nos indica a pesquisa de Souza (2004). As matérias de Desenho Linear e Desenho Geométrico deixaram de fazer parte das propostas e a matéria de Desenho passa a se relacionar mais com o ensino de desenho do natural. Por outro lado, a Geometria, que aparecia somente nos últimos anos do ensino primário, move-se, também, para os anos iniciais. Outras preocupações passaram a incorporar a sua proposta, como o estudo dos sólidos geométricos e as construções geométricas, além da geometria plana que já existia desde o início da república. A matéria de Trabalhos Manuais se movimenta na direção de auxiliar os estudos geométricos, inserindo o uso de instrumentos de desenho e o trabalho de modelagem em suas propostas metodológicas.

No que se referem aos métodos verificamos que a partir do programa de 1917 a estruturação dos conteúdos leva a crer uma aproximação da abordagem analítica, partindo primeiro das figuras tridimensionais e segue para as figuras bidimensionais e unidimensionais. Também foi possível verificar a inserção do manuseio de materiais geométricos e o trabalho com a construção de sólidos geométricos, ações que indicam o uso de princípios do método intuitivo para o ensino de saberes geométricos.

\section{b. MÉTODOS E CONTEÚDOS NOS LIVROS DIDÁTICOS}

Diante da complexidade do estudo do tema "métodos e conteúdos" para o ensino de saberes geométricos nos primeiros anos escolares, torna-se necessário insistirmos em pesquisas que visem a uma melhor compreensão das apropriações realizadas pelos professores. Acreditamos que uma estratégia possível seja o estudo dos livros didáticos, pois ao considerarmos obras que tiveram grande circulação no ensino podemos ter a possibilidade de inferir os usos de possíveis 
métodos em práticas de sala de aula. Lembramos que livros didáticos são desenvolvidos por meio de variadas apropriações e determinações, neste sentido:

[...] obras didáticas não irão revelar o método em si, a sua pureza, a sua própria definição epistemológica transposta para o texto escolar. Cruzamentos, apropriações, adaptações diversas estão presentes nos textos didáticos. A análise dos livros mostra a convivência de métodos e processos diferentes numa mesma obra. (VALENTE, 2015, p. 205).

Em presença das prescrições metodológicas e programáticas para o ensino primário paranaense, quais seriam os livros propostos para o ensino de saberes geométricos? Como os conteúdos geométricos e os métodos de ensino se apresentam nestes livros?

No início do século $X X$ já estava em pauta a preocupação com a unificação dos livros didáticos, Relatório do Secretário do Interior, Justiça e Instrução Pública, Bento José Lamenha Lins, ao Presidente do estado do Paraná, Vicente Machado da Silva Lima, apontava para a grande dificuldade que passava o estado do Paraná. "O ensino primário não está uniformizado nem quanto aos livros, nem quanto aos métodos, sendo urgente organizar a serie de livros para as classes de acordo com o adiantamento das mesmas" (PARANÁ, 1904, p. 23).

Percebe-se que havia dificuldade no processo de uniformização tanto de livros didáticos quanto de métodos de ensino, em que o livro didático representava uma forte presença na reorganização pedagógica da instrução pública primária paranaense. É o livro didático fazendo parte de estratégias nas propostas de renovação pedagógica.

O Regimento Interno de 1903, apresentava em anexo uma lista de livros que deveriam ser adotados, entre eles o livro "Geometria Prática", de Olavo Freire. Já o Regulamento de $1907^{11}$ estabelecia quais os livros deveriam ser adotados, porém poderiam em qualquer ocasião ser ampliados em número ou substituído por outros, a juízo do governo (art. 468, Das Disposições Gerais e Transitórias do Regulamento da Instrução Pública do Estado do Paraná, 1907). No que se refere ao saber geométrico, na relação de títulos apresentada neste regulamento continua sendo indicado o livro de Olavo Freire.

11 Este regulamento foi revogado um mês após ser colocado em execução. 


\section{Atos de Pesquisa em Educação - ISSN 1809-0354 \\ Blumenau, v. 12, n.2, p.324-345, mai./ago. 2017 \\ DOI: http://dx.doi.org/10.7867/1809-0354.2017v12n2p324-345}

Ao final do documento que consta o programa de 1916 há uma outra lista com os livros que deveriam ser adotados nas escolas. Para o ensino de Geometria era indicado o livro "Desenho Linear", de Abílio C. Borges, para a $3^{a}$ série. Para a $4^{a}$ série, a indicação era o livro Geometria Prática de Olavo Freire.

O livro didático intitulado "Desenho linear de elementos de Geometria prática popular: seguido de lições de agrimensura stereometria e architectura" - "Primeira Parte"12, de Abílio Cesar Borges $^{13}$, foi editado e publicado em 1882, Tipografia Aillaud e livraria Francisco Alves.

Para Abílio César Borges, o Desenho tinha uma importância fundamental na instrução primária "porque esclarece e dá tempera ao espírito sem fatigá-lo, enriquecendo-o com numerosíssimas idéias exactas e constante applicação prática, desperta a faculdade da observação, e, portanto, o gosto de aprender" (BORGES, 1884, Introdução, p. II). Abílio inicia o livro definindo Desenho Linear como "também chamado geométrico, é a arte de representar por meio de linhas os contornos das superfícies e corpos (p.1)". Acrescenta que o ensino do Desenho foi organizado em seu livro em "marcha naturalmente progressiva, procedendo passo a passo, subindo docemente, como por degráos insensíveis, das idéias mais simples ás mais complicadas e usando de uma linguagem calculadamente concisa, singela e clara" (BORGES, 1884, Introdução, p.XII).

$\mathrm{Na}$ referida obra a preocupação encontra-se em conceituar e definir cada forma geométrica e seus componentes, apresentando graficamente suas imagens e identificando seus elementos, sem apresentar descritivamente o processo de construção de cada uma delas. $\mathrm{Na}$ introdução são apresentadas definições preliminares como espaço, superfície e linhas. Nos capítulos I, II e III o autor apresenta definições do ponto e de linhas em geral, no capítulo IV trabalha com ângulos, nos capítulos V, VI e VII, com polígonos, no capítulo VIII com figuras

12 Para saber mais sobre essa obra recomendamos o artigo de Glaucia Trinchão "O conhecimento em desenho das escolas primárias imperiais brasileiras: o livro de desenho de Abílio César Borges". História da Educação, ASPHE/FaE/UFPel, Pelotas, n. 23, p. 125-147, Set/Dez 2007. Disponível em: http//fae.ufpel.edu.br/asphe.

13 Abílio Cesar Borges, também chamado de Barão de Macaúbas, era médico, mas sua maior contribuição ao país foi como educador. Em 1856, foi nomeado diretor da Instrução Pública na Bahia, onde fundou Ginásio Baiano e o Colégio Abílio. 
formadas por linhas curvas e nos capítulos IX, X e XI são desenvolvidos os estudos de sólidos geométricos.

O compêndio Primeiras Noções de Geometria Prática, de Olavo Freire, ${ }^{14}$ está presente em todas as indicações de livros na fase pesquisada. Foi publicado pela primeira vez em 1894, aprovado e premiado pelo Conselho de Instrução Pública do Distrito Federal e propõe o ensino de uma geometria elementar destinada aos alunos da escola primária.

A geometria se apresenta distribuída em vinte e um capítulos, sendo os doze primeiros destinados ao estudo da geometria plana, finalizando com o cálculo de áreas de polígonos. Os demais capítulos são reservados para a geometria espacial que incluem também o cálculo de áreas e volumes dos poliedros e corpos redondos e o estudo das cônicas, no último capítulo.

Em ambos os livros considerados, os autores apresentam primeiro as noções preliminares (espaço, superfície, retas, ângulos), seguidas da Geometria Plana (triângulos, quadriláteros, círculo, circunferência, polígonos) e posteriormente a Geometria Espacial (poliedros, corpos redondos). Essa forma de selecionar e organizar os conteúdos configura o método sintético, isto é, segue o caminho das partes para o todo. Percebe-se a necessidade do desenvolvimento de um processo lógico-dedutivo para se chegar a novos conhecimentos com base nos anteriores, evidenciando a metodologia utilizada pelos Elementos de Euclides.

Tomemos a definição do conceito de ângulo desenvolvido nas duas obras. Olavo Freire inicia o capítulo colocando que "ângulo é o maior ou menor afastamento de duas linhas que se encontram" (FREIRE, 1930, p. 27). A seguir, o autor apresenta imagens de uma tesoura e de um compasso abertos, para que esses objetos comuns possam auxiliar na compreensão do conceito. Na segunda obra é apresentada a definição de ângulo como sendo "a extensão superficial ou o plano comprehendido entre duas linhas que se encontram" (BORGES, 1884, p. 20). Também são observadas figuras, porém sem relação com objetos cotidianos.

Figura 1 - Conceito de ângulo

\footnotetext{
${ }^{14}$ Para maiores detalhes sobre a obra temos o artigo de Maria Célia Leme da Silva "A prática da geometria prática no ensino primário: subsídios para uma história disciplinar" apresentado na $33^{a}$ Reunião Anual da ANPEd, em Caxambu, 2010.
} 

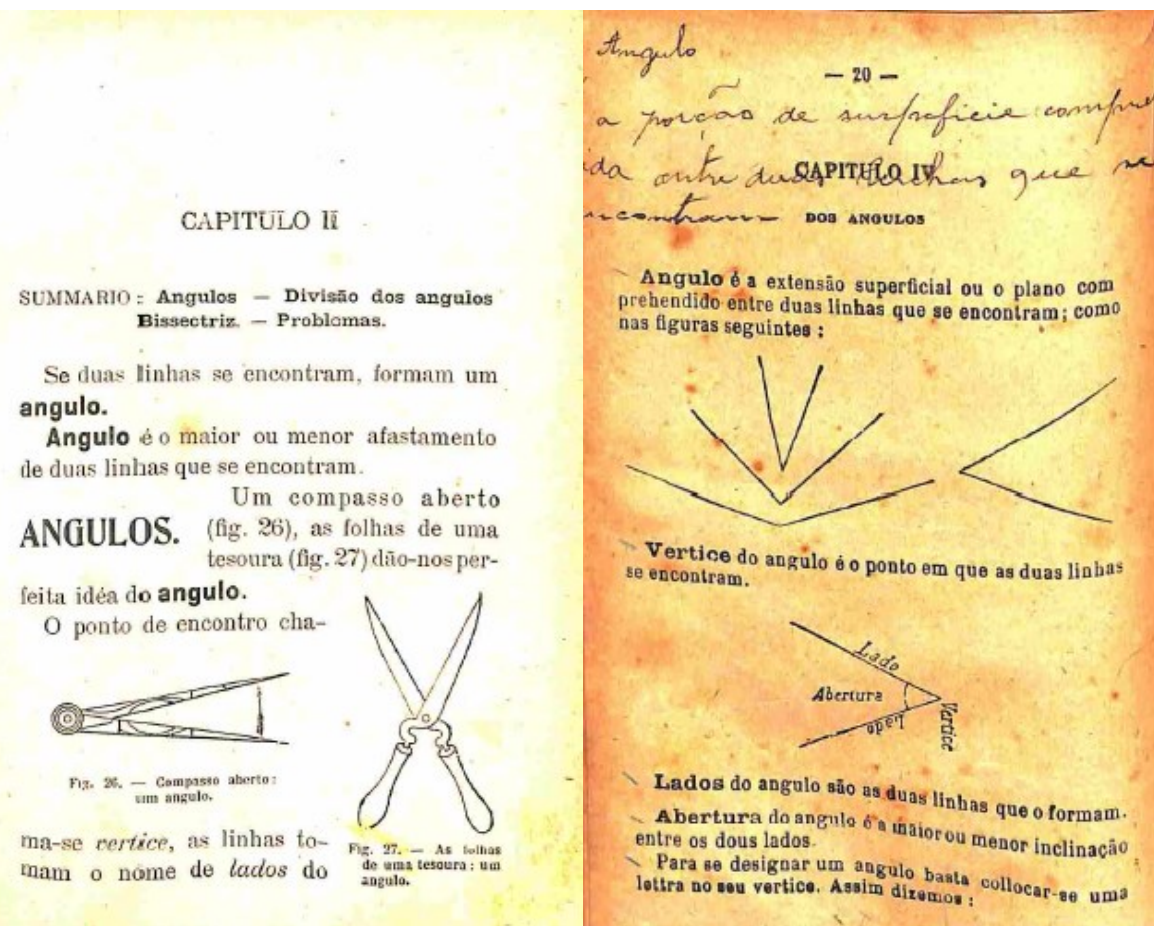

Fonte: FREIRE, 1930, p. 27 e (BORGES,1884, p. 20)

Verifica-se que a geometria proposta no livro de Freire tem um enfoque mais prático, ao relacionar os conceitos apresentados com objetos e ferramentas da vida diária em vários momentos da obra. Não podemos afirmar que a obra de Olavo Freire se apresenta completamente por meio de um processo intuitivo, porém em várias situações são apresentados exemplos de uso cotidiano, chamando o concreto e o sensível das crianças para o desenvolvimento dos conteúdos.

Segundo Leme da Silva e Frizzarini (2014), o compêndio "Primeiras Noções de Geometria Prática", de Olavo Freire, marca a introdução de novas práticas no ensino primário, desenvolvidas por meio do uso de instrumentos (régua e compasso) para a construção de figuras geométricas. Até então, as figuras eram traçadas à mão livre, como um exercício e treino do olhar e neste sentido a obra constitui-se como um compêndio inovador. Segundo as autoras as construções geométricas também estão inseridas na denominada geometria prática.

A manipulação é uma marca da pedagogia moderna, porém o manuseio dos instrumentos geométricos para a construção de figuras mostra-se como um ensino a partir de passos rígidos e pré-determinados, onde são realizadas cópias de exercícios já realizados. As atividades de construção geométrica indicadas na obra 
apresentam uma sequência preocupada com a linearidade do ensino e com os prérequisitos existentes, indicando mais uma vez que características do método sintético estavam presentes no contexto do ensino de saberes geométricos na época pesquisada.

\section{ALGUMAS CONSIDERAÇÕES}

O início dos grupos escolares e do ensino seriado no estado do Paraná promove a ocorrência de alterações na organização e na condução do ensino primário em que a discussão de novos métodos e conteúdos foi um elemento essencial para a reformulação do ensino.

O método de ensino intuitivo foi implantado à medida que novas configurações eram estabelecidas ao ensino primário, um ensino que enfatizasse os sentidos, a observação, o objeto concreto e a experimentação são explicitamente apresentados nos regulamentos, programas e relatórios que se fizeram presentes neste período.

No que tange aos conteúdos verificamos que houve um intenso movimento dos saberes geométricos nos programas do período. As matérias de Desenho Linear e Desenho Geométrico deixaram de fazer parte das propostas e a matéria de Desenho passa a se relacionar mais com o ensino de desenho do natural. A Geometria passa a ser uma matéria presente em todos os anos do ensino primário. Seu ensino parte das figuras tridimensionais e segue para as figuras bidimensionais e unidimensionais; o manuseio de instrumentos de construção geométrica e a construção de sólidos geométricos com material concreto começam a fazer parte do programa, tanto na disciplina de Geometria como na de Trabalhos Manuais. A forma como as novas estruturações dos conteúdos foi sendo desenvolvida pode facilitar as abordagens intuitiva e analítica para o ensino de saberes geométricos.

Verificamos que, tanto nas propostas pedagógicas discutidas por professores e outros profissionais quanto nos programas de ensino, os métodos intuitivo e analítico eram os mais indicados para o ensino dos saberes geométricos no ensino primário. Porém, ao analisarmos os livros didáticos não observamos uma apresentação e organização de conteúdos que facilitasse o desenvolvimento desses 
tipos de métodos. Nos dois livros indicados percebe-se que apenas uma das obras apresenta o método intuitivo de forma mais clara no desenvolvimento da proposta e que ambas se preocupam com uma seleção e organização dos conteúdos partindo das partes para o todo o que indica uma maior preocupação com o uso do método sintético.

Considerando os documentos analisados verificamos que os métodos intuitivo, sintético e analítico se faziam presentes no contexto educacional da época. Esta é uma primeira indicação sobre a pertinência de se analisar os saberes geométricos diante os variados métodos de ensino. Qual a relação do método intuitivo com a análise e a síntese? Será que esses métodos eram utilizados nas práticas de sala de aula? Essas são apenas algumas entre as inúmeras questões que surgem diante a discussão que está sendo desenvolvida.

Sabemos que os regulamentos, programas de ensino e livros didáticos são elaborados por múltiplas apropriações e determinações. Por isso, necessitamos de muitos cruzamentos e análises de vestígios da época para termos uma melhor compreensão de como esses métodos de ensino poderiam ou não influenciar as práticas dos professores do ensino primário no início do século XX. Torna-se necessário insistirmos em uma maior aproximação sobre o ensino dos saberes geométricos, procurando compreender as variadas apropriações em termos de métodos e conteúdos na escola primária.

\section{ALEXSANDRA CAMARA}

Doutoranda do curso de Pós-Graduação em Educação da Pontifícia Universidade Católica do Paraná-PUCPR.

\section{NEUZA BERTONI PINTO}

Doutora em Educação pela Universidade de São Paulo (USP), Grupo de Pesquisa em História da Educação e Matemática - GHMAT, Rede Amazônica de Educação em Ciências em Matemática- REAMEC - UFMT.

\section{REFERÊNCIAS}

A ESCHOLA PUBLICA. São Paulo, SP: Typ. da Industrial de São Paulo, ano 2, n. 8, dez. 1897. Disponível em:

$<$ http://repositorio.ufsc.br/xmlui/handle/123456789/126747>. Acesso em: 20 jun. 2016. 
ANJOS, J. J. T. A Hemeroteca Professor Osvaldo Pilotto, na Biblioteca do Museu Paranaense: Um Acervo Para as Pesquisas em História da Educação no Paraná (1857-1946). X CONGRESSO NACIONAL DE EDUCAÇÃO - EDUCERE. CURITIBA, 2011. Disponível em: http://educere.bruc.com.br/CD2011/pdf/4319_2372.pdf. Acesso em: 20 mai. 2014.

BORGES, A. C. Desenho Linear ou Elementos de Geometria Prática Popular, seguidos de algumas noções de Agrimensura, Stereometria e Architectura. Primeira Parte. $8^{\mathrm{a}}$ ed. destinada especialmente as escolas primárias. Bruxelas: Typografia e Lithografia E. Guyot, 1884.

CHARTIER, R. A História Cultural: entre práticas e representações. Lisboa: DIFEL, 1990.

CHERVEL, A. História das disciplinas escolares: reflexões sobre um campo de pesquisa. Porto Alegre: Pannonica, Teoria \& Educação. n. 2, 1990.

CHEVALLARD, Y. La Transposition didactique. Du savoir savant au savoir enseigné. Grenoble, La Pensée sauvage, 1985.

CORREA, B. M. A introdução à arte analítica de François Viète: comentários e tradução. 2009. 131 f. Dissertação (Mestrado) - UFRJ/IM. Programa de Pósgraduação em Ensino de Matemática, 2009.

FREIRE, O. Noções de Geometria Prática. $35^{\mathrm{a}}$ ed. Livraria Franscisco Alves, Rio de Janeiro, 1930.

FRIZZARINI, C. R. B. OLIVEIRA, M. A. SILVA, M. C. L. e VALENTE, W. R. Os Saberes Elementares Matemáticos e os Programas de Ensino. São Paulo (18941950). In COSTA, D., VALENTE, W. R., (orgs.). Saberes Matemáticos no Curso Primário: o que, como e porque ensinar? 1ed. - São Paulo: Editora Livraria da Física, 2014.

FRIZZARINI, A. R. B. e LEME DA SILVA, C. . Primeiras Noções de Geometria Prática de Olavo Freire: um compêndio inovador? Anais Eletrônicos do $14^{\circ}$ Seminário Nacional de História da Ciência e da Tecnologia - 14 SNHCT, 2014. Disponível em: www.14snhct.sbhc.org.br/arquivo/download?ID_ARQUIVO=1820. Acesso em: 20 jul. 2015.

JULIA, D. A cultura escolar como objeto histórico. In: Revista Brasileira de História da Educação, v. 1, n. 1, jan./jun., p. 9-43, 2001.

LEME DA SILVA, M. C. A prática da geometria prática no ensino primário: subsídios para uma história disciplinar. Anais da $33^{a}$ ANPEd, 2010. Disponível em: http://33reuniao.anped.org.br/33encontro/app/webroot/files/file/Trabalhos $\% 20 \mathrm{em} \% 20$ PDF/GT19-6263--Int.pdf. Acesso em: 20 mai. 2014. 
. Revista A Eschola Publica (1896-1897): Saberes Geométricos e o Método Analítico. XII Seminário Temático Saberes Elementares Matemáticos do Ensino Primário (1890 - 1971): o que dizem as revistas pedagógicas. PUCPR, 2015. Disponível em: http://www2.td.utfpr.edu.br/seminario_tematico/artigos/55.pdf. Acesso em: 21 jun. 2016.

LOURENÇO FILHO, M. B. Introdução ao estudo da escola nova: bases, sistemas e diretrizes da pedagogia contemporânea. 14.ed. EdUERJ, 2002.

MIGUEL, M. E. B. A formação do professor e a organização social do trabalho. Curitiba: Ed. da UFPR, 1997.

PILOTTO, E.. Methodologia de Geometria. Trad. e adap. da obra de J. Patrascoiu. Bilbioteca Pública do Estado do Paraná, 1926.

PINTO, N. B. História das disciplinas escolares: reflexão sobre aspectos teóricometodológicos de uma prática historiográfica. In: Revista Diálogo Educacional, Curitiba, v. 14, n. 41, p. 125-142, jan./abr. 2014. Disponível em:

file:///C:/Users/alcamara/Downloads/dialogo-12619.pdf. Acesso em: 20 mai. 2014.

ROCHA, A. R. Relatório apresentado ao Diretor Geral da Instrucção In: Revista A Escola, v. 2, 1906.

SOUZA, G. Instrução, o talher para o banquete da civilização: cultura escolar dos jardins-de-infância e grupos escolares no Paraná, 1900-1929. 2004. Tese (Doutorado). Universidade Pontifícia Universidade Católica de São Paulo, 2004

SOUZA, R. F.. Alicerces da Pátria: história da escola primária no estado de São Paulo (1890 - 1976). Campinas - São Paulo: Mercado das Letras, 2009.

. Inovação educacional no século XIX: a construção do currículo da escola primária no Brasil. In: Cadernos Cedes, ano XX, n 51, p.9-28, novembro de 2000.

TRINCHÃO, G. O conhecimento em desenho das escolas primárias imperiais brasileiras: o livro de desenho de Abílio César Borges. História da Educação, ASPHE/FaE/UFPel, Pelotas, n. 23, p. 125-147, Set/Dez 2007. Disponível em: http://seer.ufrgs.br/asphe/article/view/29274. Acesso em: 20 mai. 2014.

VALDEMARIN, V. T. O Método Intuitivo: os sentidos como janelas que se abrem para um mundo interpretado. In: SOUZA, R. F.; VALDEMARIN, V. T.; ALMEIDA, T. S. (Orgs). O legado Educacional do século XIX. UNESP: Araraquara, Faculdade de Ciências e Letras, 1998.

VALENTE, W. R. Tempos de Império: a trajetória da geometria como um saber escolar para o curso primário. Revista Brasileira de História da Educação, v.12, p. 73-94, 2012. Disponível em: 
Atos de Pesquisa em Educação - ISSN 1809-0354

Blumenau, v. 12, n.2, p.324-345, mai./ago. 2017

DOI: http://dx.doi.org/10.7867/1809-0354.2017v12n2p324-345

http://www.rbhe.sbhe.org.br/index.php/rbhe/article/view/446. Acesso em: 20 mai. 2014.

. Como Ensinar Matemática no Curso Primário? Uma questão de conteúdos e métodos, 1890-1930. Perspectivas em Educação Matemática. Revista do programa de pós-graduação em Educação Matemática da Universidade Federal de Mato Grosso do Sul (UFMS). Volume 8, Número 17, p. 192-2017, 2015.

VIĖTE, F. L'Algèbre nouvelle de Mr. Viète. Tradução de A. Vasset, 1630. Disponível em: http://gallica.bnf.fr/ark:/12148/bpt6k108864f. Acesso em: 28 mai. 2007.

\section{PROGRAMAS, REGULAMENTOS E LEIS DO PARANÁ}

PARANÁ. Regulamento da Instrução Pública do Estado do Paraná. Francisco Xavier da Silva e Octavio Ferreira do Amaral e Silva, 1901, PR. Disponível em:

https://repositorio.ufsc.br/xmlui/handle/123456789/123700. Acesso em: 20 jun. 2016.

PARANÁ. Regimento Interno das Escolas Públicas do Estado do PR. Amaral e Silva, Octavio Ferreira do, 1903. Disponível em:

https://repositorio.ufsc.br/xmlui/handle/123456789/134515. Acesso em: 20 jun. 2016.

PARANÁ. Relatório apresentado por Bento José Lamenha Lins, Secretaria D’Estado dos Negócios do Interior, Justiça e instrução pública ao Presidente do Estado, 1904, PR. https://repositorio.ufsc.br/handle/123456789/99854

PARANÁ. Regulamento Orgânico do Ensino Público do Estado do Paraná, 1909, PR. Francisco Xavier da Silva. Disponível em: http://repositorio.ufsc.br/xmlui/handle/123456789/99855. Acesso em: 20 jun. 2016.

PARANÁ. Programas de ensino e sua execução nos institutos públicos do curso primário. Conselho Superior do Ensino Primário, PR, 1916. Disponível em:

https://repositorio.ufsc.br/xmlui/handle/123456789/123959. Acesso em: 20 jun. 2016.

PARANÁ. Programa dos Grupos Escolares do Estado do Paraná. Marins Alves de Camargo. 1921, PR. Disponível em:

https://repositorio.ufsc.br/handle/123456789/105310. Acesso em: 20 jun. 2016.

PARANÁ. Portaria n. 4 de 17 de Janeiro de 1914. Instruções para reorganização das escolas públicas. Diretoria da Instrução Pública. In: MACEDO, Francisco Ribeiro de Azevedo. Relatório apresentado ao cidadão Dr. Claudino Rogoberto F. dos Santos Secretário d'Estado dos Negócios do Interior. Justiça e Instrução Pública pelo Diretor Geral da Instrução Pública. (s.n.t.). 
PARANÁ. Relatório do Secretário de Estado dos Negócios do Interior, Justiça e instrução pública. Claudino Rogoberto Ferreira dos Santos, 1913. Disponível em: http://repositorio.ufsc.br/xmlui/handle/123456789/99955. Acesso em: 12 dez. 2015

PARANÁ. Relatório do Diretor Geral da Instrução Pública, 1903. Victor Ferreira do Amaral e Silva. Disponível em:

http://repositorio.ufsc.br/xmlui/handle/123456789/99762. Acesso em: 12 dez. 2015.

PARANÁ. Código de Ensino (PR. Decreto $\left.n^{\circ} 710 / 1915\right)$. Carlos Cavalcante Albuquerque e Claudino Rogoberto Ferreira dos Santos. Disponível em: http://repositorio.ufsc.br/xmlui/handle/123456789/99744. Acesso em: 12 dez. 2015.

PARANÁ. Programa de Ensino do Grupo Escolar "Modelo" e Similares. Diário Oficial do Estado do Paraná, meses de Jun/Jul/Ago de 1917. 